\title{
A comparison of degree and diploma nursing students confidence of patient safety competency in Ontario, Canada
}

\author{
June Raymond* \\ Cambrian College of Applied Arts and Technology, Ontario, Canada
}

Received: February 22, 2017

Accepted: March 12, 2017

Online Published: March 20, 2017

DOI: $10.5430 /$ jnep.v7n8p93

URL: https://doi.org/10.5430/jnep.v7n8p93

\begin{abstract}
In Ontario, Canada, Registered Nurses and Practical Nurses practice autonomously and safely in the healthcare system. Students who are aiming to become a Registered Nurse are enrolled in a four-year university baccalaureate degree program while students pursuing a practical nursing diploma are registered in a two or three-year college program. Exploring differences in confidence levels could provide insight into whether one type of nursing educational program is assisting students to develop higher confidence levels on patient safety topics. The Health Professional Education in Patient Survey was used for data collection in this research study. In total, 206 practical nursing students and 458 degree nursing students participated in this study from four different academic settings in Ontario, Canada. Overall, students in both types of educational programs expressed similar levels of confidence on the seven patient safety subscales. Practical nursing students feel errors are viewed as individual mistakes and they fear repercussions when they make a mistake more so than degree students. Although the categories of students receive different education in terms of length of program, setting, and depth of content, students within either type of program appear to develop confidence levels that are similar for the most part.
\end{abstract}

Key Words: Nursing education, Nursing student, Confidence, Patient safety

\section{INTRODUCTION/BACKGROUND}

Concerns with the quality of care that patients experience is not a new topic in the health care industry. It was sparked by the Institute of Medicine's (IOM) landmark report, To Err is Human that revealed that every year in the United States (US) alone roughly 98,000 patients attending acute care facilities experience a patient safety event and that nearly half of these are preventable. ${ }^{[1]}$ This original report led to worldwide initiatives aimed at improving the state of health care. A recent report revealed that in the US medical errors are the third leading cause of death for 10 percent of the population amounting to approximately 251,000 annually. ${ }^{[2]}$ In Canada,
Baker and colleagues (2004) explored acute care records and found an error rate of 7.5\%. ${ }^{[3]}$ In 2013, other researchers noted a 10\%-13\% error rate in records from community care settings. ${ }^{[4,5]}$

The IOM in light of these patient safety concerns recommended that health education programs be transformed to include additional patient safety content and common safety language. ${ }^{[6-8]}$ Following the IOM's recommendations, governments and private agencies funded initiatives that led to the development of patient safety institutions and frameworks. ${ }^{[9-11]}$ These guides were developed to assist with health education curriculum review and designed to aid in Canada.

Published by Sciedu Press 
curriculum transformation. In Canada, the Canadian Patient Safety Institute developed the Canadian Patient Safety Framework (CPSF) which is based on six domains, competencies, and related knowledge, skills, and attitudes. ${ }^{[10]}$ The six domains include: safety culture; working in teams; effective communication; risk management; environment and human factors; and adverse events. ${ }^{[10]}$

Although all health care providers have a duty to provide safe care, nurses have the greatest potential to influence the quality of care that a patient receives as they are the group of care providers with the greatest direct patient contact for extended periods of time. ${ }^{[12,13]}$ Patient complexity and acuity have dictated the need for expanded nursing roles and changes to educational requirements and Ontario has responded with the various levels of nursing professionals practicing within the province. In Ontario, Canada there are two classifications of nurses: Registered Nurses (RNs) which includes Nurse Practitioners and Registered Practical Nurses (RPNs) also referred to as Licensed Practical Nurses in other provinces in Canada. ${ }^{[14]}$ The educational requirement for RNs is a four-year university degree culminating in a bachelor's degree and a two or three-year college diploma for RPNs. ${ }^{[14]}$ Since RNs receive either an additional year or two of formal education this should theoretically result in graduates that have a deeper more comprehensive knowledge base, leadership, and decision making skills. ${ }^{[15]}$ RPNs, due to the shorter duration of their formal education, obtain a more focused education. ${ }^{[15]}$ The two types of education are very different but both produce bedside nurses.

Along with increased educational requirements came expanded scopes of practice for both categories of nurses. Although the term 'scope of practice' is used extensively throughout literature and job descriptions there is no consistent definition. For the purpose of this paper, the Health Authorities Health Professions Act Regulations Review Committee's (2002) definition of scope of practice as what one has been educated on, is competent to do, and is legally authorized to perform. ${ }^{[16]}$ The levels of autonomy in practice differs between the two classes of nurses and the degree of complexity and stability dictates which class of nurse should provide care. ${ }^{[17]}$ RNs have more autonomy when caring for complex unstable patients. ${ }^{[17]}$

While the education process may differ, both categories of nurses have standards of practice and entry-to-practice competencies and licensing examinations. ${ }^{[18]}$ The composition of care providers is unique to each healthcare setting and is often staffed with a combination of RNs, RPNs and unregulated healthcare professionals practicing together. Ideally, the care provided is of better quality when they are practicing collaboratively. The CNO reported that there were approximately 104,298 practicing RNs and 42,018 RPNs practicing in Ontario in 2014. ${ }^{[19]}$

As the nursing students of today are the practitioners of tomorrow, nursing students are a cohort of resources that require focus. When exploring nursing students in relation to patient safety, it is important to consider their self-confidence as it is a direct indicator of their performance. Students enrolled in Nurse Practitioner programs are outside the scope of this research study. This study has focused on collecting perceptions of confidence on patient safety topics from nursing students enrolled in programs dedicated to educating and preparing RNs and RPNs. It is important to gain an understanding of what the students' confidence levels are and whether there is a difference in the confidence levels between the different categories of nursing students. This can provide valuable insight and recommendations into what path the future of nursing education should take. The aim of this study was to explore if there are differences between degree nursing students and college nursing students' confidence levels on patient safety topics.

This study is unique in that no research that could be found that explores both classes of nursing student confidence on patient safety topics. The research question for this study was: What are the similarities and differences in the level of students' confidence of patient safety between baccalaureate prepared degree nursing students and practical diploma prepared nursing students?

\section{Methods}

\subsection{Sample}

This quantitative cross-sectional descriptive comparative study collected students' perspectives from four different academic settings within Ontario, Canada. Two college settings and two university settings were selected and students from all years of the programs were collected. The students from the university programs were enrolled in four-year degree nursing programs. The students from the college programs were enrolled in two-year diploma nursing programs. Students needed to have computer and Internet access and be able to write and read English. The plan was to exclude any students who had not participated in at least one clinical placement however there were no students excluded based on this criterion.

\subsection{Study instrument}

The modified web version of the Health Professional Education in Patient Safety Survey (H-PEPSS), was used for data collection. ${ }^{[20-22]}$ Permission to use this tool in this research study was obtained from its developers. This tool was 
validated and confirmed to have an internal consistency reliability greater than .80 and acceptable indices of fit. ${ }^{[20,21]}$ This tool was based on the CPSF and consists of three sections with 38 items in total. The first section of the tool has 27 questions has the students express their level of confidence using a 5 -point Likert scale ( $1=$ strongly disagree, $2=$ disagree, $3=$ neutral, $4=$ agree, $5=$ strongly agree, and there was also a 'don't know' option) on the six domains as per the CPSF (clinical safety, working in teams, communicating effectively, managing safety risks, understanding human and environmental factors, recognizing and responding to adverse events, and culture of safety) together with one additional subscale entitled clinical safety that included skills related topics including: hand hygiene, infection control, and medication administration. The next two sections are made up of 7 and 4 questions respectively and ask students to rate use the 5-point Likert scale as section one (except there was not a 'don't know' option). The specific questions related to broader safety issues and comfort levels speaking up.

\subsection{Ethics and data collection procedure}

Ethical approval was obtained from the research ethics board for all participating institutions. Following ethical approval, an administrative staff member from each institution's nursing department was sought to assist in the recruitment of participants. The staff members forwarded, on behalf of the researcher, the invitations to students via email during the 2014-15 academic year. In total, the nursing administrative members reported that 2,100 students were eligible and invited to participate. Six hundred and sixty-eight responses were received in total. Out of these responses four were missing the majority of the responses and deemed unusable. This left 664 usable responses (31.6\% response rate). Two email reminders were sent to all students eligible to participate at two week intervals.

\subsection{Analysis}

IBM SPSS Statistics for Macintosh, Version 22.0, was used to analyze the data. Means and standard deviations were calculated for each of the seven subscales in the first section of the survey. The two college and two university programs were each recoded into new variables with data from the university students combined $(\mathrm{n}=458)$ and the data from the college students combined $(\mathrm{n}=206) . T$-tests were used to compare differences between the degree and diploma nursing students' perspectives on their confidence levels for each of the 27 questions individually and then on the seven patient safety subscales.

For the second and third sections of the H-PEPSS, mean summary scores were calculated by dichotomizing the scale into categories. Responses 4 and 5 on the scale were converted to Published by Sciedu Press the 'agree' category and 1 to 3 were converted to 'disagree or neutral'. Percentages of students who agree/disagree with the statements were calculated and the two groups of students further compared using Chi square testing (confidence interval set at $95 \%$ ).

\section{RESULTS}

The majority of the participants were female between the ages of 18-27. Table 1 displays the demographic details of the participants.

Table 1. Participant Demographics $(n=664)$

\begin{tabular}{lll}
\hline Variables & $\mathbf{N}$ & $\mathbf{\%}$ \\
\hline Gender & 38 & 6 \\
Male & 626 & 94 \\
Female & & \\
Age (years) & 256 & 38 \\
$18-22$ & 312 & 47 \\
$23-27$ & 66 & 10 \\
$28-32$ & 24 & 4 \\
$33-40$ & 6 & 1 \\
$41-45$ & & \\
Educational Institution & 100 & 15 \\
College A & 106 & 16 \\
College B & 208 & 31 \\
University A & 250 & 38 \\
$\quad$ University B & & \\
Educational Program & 458 & 69 \\
Degree & 206 & 31 \\
$\quad$ Diploma &
\end{tabular}

Table 2 displays the means and standard deviations for the seven subscales for each of the four institutions. All four groups of students expressed their highest level of confidence on clinical safety issues including medication topics, hand hygiene, and infection control regardless of their program type. These topics are more tangible and easier to observe which could be the reason for higher confidence on these topics. It is evident from Table 2 that both groups of degree students consistently expressed higher confidence levels than both groups of diploma students for all of the seven subscales.

After combining the two groups of students for the two program types, the means for each of the 27 questions contained in section one of the tool were compared using $t$-tests and tested for equality with the Levene's test (Field, 2009). Mean difference significance was set at .50 as this researcher believes that this would be the minimum difference that would be required to indicate educational significance. Only the statements that reflected a significant difference are displayed in Table 3. 
Table 2. Safety Subscales by Educational Institutions

\begin{tabular}{lllll}
\hline Subscale & College A & College B & University A & University B \\
\hline Clinical Safety & $4.27(.36)$ & $4.31(.44)$ & $4.53(.44)$ & $4.58(.44)$ \\
Working in Teams & $3.80(.29)$ & $3.82(.43)$ & $4.17(.46)$ & $4.20(.50)$ \\
Communicate Effectively & $4.08(.28)$ & $4.15(.40)$ & $4.40(.42)$ & $4.39(.48)$ \\
Manage Safety Risks & $3.89(.27)$ & $3.88(.43)$ & $4.23(.48)$ & $4.29(.52)$ \\
Human and Environment & & & \\
$\quad$ Factors & $3.70(.41)$ & $3.73(.55)$ & $4.14(.47)$ & $4.27(.52)$ \\
Adverse Events & $3.90(.25)$ & $3.83(.43)$ & $4.16(.44)$ & $4.25(.51)$ \\
Culture of Safety & $3.85(.28)$ & $3.85(.51)$ & $4.08(.40)$ & $4.20(.47)$ \\
\hline
\end{tabular}

After individual questions were combined into their appro- tionally significant differences noted in Table 3 below, $t$-tests priate subscales mean differences were again calculated. Al- revealed no educationally significant differences based on a though there were eight individual statements with educa- significant level of .50 on any of the subscales.

Table 3. Differences Between Degree and Diploma Students for Individual Questions

\begin{tabular}{|c|c|c|c|}
\hline Questions & $\begin{array}{l}\text { RN Degree Students } \\
\text { Mean (SD) }\end{array}$ & $\begin{array}{l}\text { RPN Diploma Students } \\
\text { Mean (SD) }\end{array}$ & $\begin{array}{l}\text { Mean } \\
\text { Difference }\end{array}$ \\
\hline $\begin{array}{l}\text { I feel confident in what I am learning about team dynamics and } \\
\text { authority/power differences in the classroom. }\end{array}$ & $4.34(.67)$ & 3.79 (.59) & .550 \\
\hline $\begin{array}{l}\text { I feel confident in what I am learning about managing } \\
\text { inter-professional conflict in the classroom. }\end{array}$ & $4.13(.76)$ & $3.50(.71)$ & .626 \\
\hline $\begin{array}{l}\text { I feel confident in what I am learning about managing } \\
\text { inter-professional conflict in the clinical settings. }\end{array}$ & $3.82(.78)$ & $3.15(.84)$ & .671 \\
\hline $\begin{array}{l}\text { I feel confident in what I am learning about anticipating and } \\
\text { managing high risk situations in clinical settings. }\end{array}$ & $4.05(.67)$ & $3.51(.78)$ & .538 \\
\hline $\begin{array}{l}\text { I feel confident in what I am learning about the role of human } \\
\text { factors, such as fatigue, that effect patient safety in the } \\
\text { classroom. }\end{array}$ & $4.31(.65)$ & $3.69(.80)$ & .621 \\
\hline $\begin{array}{l}\text { I feel confident in what I am learning about the role of } \\
\text { environmental factors such as work flow, ergonomics, } \\
\text { resources, that effect patient safety in clinical settings. }\end{array}$ & $4.01(.67)$ & $3.44(.75)$ & .576 \\
\hline $\begin{array}{l}\text { I feel confident in what I am learning about participating in } \\
\text { timely event analysis, reflective practice and planning in order } \\
\text { to prevent recurrent in clinical settings. }\end{array}$ & $3.94(.66)$ & $3.43(.81)$ & .516 \\
\hline $\begin{array}{l}\text { I feel confident in what I am learning about the nature of } \\
\text { systems and system failures and their role in adverse events in } \\
\text { the classroom. }\end{array}$ & $4.18(.66)$ & $3.61(.79)$ & .572 \\
\hline
\end{tabular}

Diploma students expressed the least confidence on human and environmental factors with a mean of 3.72 compared to the mean of 4.21 for degree students. Degree students were least confident on topics related to culture and adverse events with a mean of 4.15. Overall, degree students expressed more confidence on all seven of the subscales. The human and environment subscale was the closest to being educationally significant which revealed a mean difference of .49 with degree students expressing more confidence than the diploma students (see Table 4).

Table 5 is a representation of the two categories of students' perspectives on broader patient safety issues addressed within their educational program taken from section two of the survey. The dichotomized data revealed that a greater percentage of degree students agreed with the statements than the diploma students for every statement except for the statement that asks whether safety is well integrated in their programs. For this item, $1 \%$ more of the diploma than degree students agreed.

The largest difference was noted in the question asking about how well system aspects such as organization, management, work environment, policies, and resources are integrated in 
their program with $86 \%$ of degree students agreeing and only $47 \%$ of practical students agreeing. Summary scores for the entire set of broader patient safety topics for each of the two categories of students were calculated. Chi square tests revealed no statistically significant differences for any of the categories. The mean for the degree students was 4.01 while the diploma students' mean was 3.73 which is not representative of an educationally significant difference with the mean difference being 28 .

Table 4. Statistical Differences by Degree and Diploma Program

\begin{tabular}{lllll}
\hline Subscale & $\begin{array}{l}\text { Degree (RN) Programs } \\
(\mathbf{n = 4 5 8 )}\end{array}$ & $\begin{array}{l}\text { Diploma (RPN) Programs } \\
(\mathbf{n = 2 0 6 )}\end{array}$ & $\mathbf{T}$ & $\boldsymbol{p}$ \\
\hline Clinical Safety & $4.56(.44)$ & $4.29(.40)$ & 7.57 & .000 \\
Working in Teams & $4.19(.48)$ & $3.81(.37)$ & 11.13 & .000 \\
Communicate Effectively & $4.39(.45)$ & $4.12(.35)$ & 8.54 & .000 \\
Managing Safety Risks & $4.26(.50)$ & $3.89(.36)$ & 10.96 & .000 \\
Human and Environment & $4.21(.48)$ & $3.72(.48)$ & 12.14 & .000 \\
Adverse Events & $4.15(.46)$ & $3.87(.35)$ & 10.22 & .000 \\
Culture of Safety & $4.15(.46)$ & $3.85(.41)$ & 8.36 & .000 \\
\hline
\end{tabular}

Table 5. Comparison of Degree and Diploma Nursing Students on Broader Patient Safety Issues

\begin{tabular}{|c|c|c|}
\hline \multirow{2}{*}{ Questions } & \multicolumn{2}{|c|}{$\begin{array}{l}\text { Numbers of Students Who Strongly Agreed or } \\
\text { Agreed (\%) }\end{array}$} \\
\hline & $\begin{array}{l}\text { Degree (RN) Students } \\
(\mathrm{n}=458)\end{array}$ & $\begin{array}{l}\text { Diploma (RPN) Students } \\
(\mathrm{n}=206)\end{array}$ \\
\hline As a student, my scope of practice is very clear to me. & $406(89)$ & $152(74)^{*}$ \\
\hline $\begin{array}{l}\text { There is consistency in how patient safety different preceptors in the } \\
\text { clinical/simulation setting deal with issues. }\end{array}$ & $262(57)$ & $88(43)^{*}$ \\
\hline $\begin{array}{l}\text { I have sufficient opportunity to learn and interact with members of } \\
\text { interdisciplinary teams. }\end{array}$ & $390(85)$ & $138(67)^{*}$ \\
\hline $\begin{array}{l}\text { I am gaining a solid understanding that reporting adverse events and close } \\
\text { calls can lead to change and can reduce reoccurrence of events. }\end{array}$ & $426(93)$ & $166(81)^{*}$ \\
\hline Patient safety is well integrated into the overall program. & $450(98)$ & $182(88)^{*}$ \\
\hline $\begin{array}{l}\text { Clinical aspects of patient safety (e.g., hand hygiene, transferring patient, } \\
\text { medication/equipment safety) are well covered in our program. }\end{array}$ & $444(97)$ & $202(98) *$ \\
\hline $\begin{array}{l}\text { "System” aspects of patient safety are well covered in our program (e.g., } \\
\text { aspects of the organization, management, or the work environment } \\
\text { including policies, resources, communication and other processes). }\end{array}$ & $396(86)$ & $96(47)^{*}$ \\
\hline $\begin{array}{l}\text { Mean summary score for the seven questions above based on a scale from } \\
1 \text { (strongly disagree) to } 5 \text { (strongly agree). }\end{array}$ & 4.01 & 3.73 \\
\hline
\end{tabular}

Table 6 displays frequencies and percentages of the two categories of nursing students and whether they agree or disagree to statements about their comfort on patient safety related topics. For all of the questions there were higher percentages of degree students who agreed with the statements than diploma students.

Sixty-five percent of degree students agreed that when an error is made the focus is on systems rather than individuals whereas only $24 \%$ of diploma students felt this way. This question parallels the response noted to the question asked in the previous selection related to 'system aspect' integration

within their curriculum. This further reiterates the need for investigation of this issue in the practical nursing programs. The mean summary scores for this section of the tool revealed a mean difference of .34 (degree-3.34; diploma-3.0), which is not significant.

\section{Discussions}

Despite the differences in educational requirements for degree and diploma students, this study did not find statistically significant nor educationally significant differences in the confidence levels between the two when comparing over- 
all subscales. However, there were significant differences noted for 8 of the individual statements and further research into these statements would yield more insight. There are a number of factors besides knowledge that can influence confidence such as previous experience, self-esteem and selfawareness. ${ }^{[23]}$

Both degree and diploma students expressed the greatest confidence on clinical safety topics, which suggests that basic skills and knowledge related to infection control, medication administration, and hand hygiene are well integrated or at least the most recognized within both nursing programs. With this study finding no significant differences in the confidence levels between the two categories of nursing students on the overall subscales it is presumed that perceptions of care, regardless of which level of nursing student is providing it, will yield a similar degree of quality based on confidence levels.

Table 6. Comparison of Degree and Diploma Nursing Students on Comfort Level Speaking Up About Patient Safety

\begin{tabular}{|c|c|c|}
\hline \multirow{2}{*}{ Questions } & \multicolumn{2}{|c|}{$\begin{array}{l}\text { Numbers of Students Who Strongly Agreed } \\
\text { or Agreed (\%) }\end{array}$} \\
\hline & $\begin{array}{l}\text { Degree (RN) } \\
\text { Students }\end{array}$ & $\begin{array}{l}\text { Diploma (RPN) } \\
\text { Students }\end{array}$ \\
\hline $\begin{array}{l}\text { If I see someone engaging in unsafe care practice in the clinical setting, I feel I } \\
\text { can approach them. }\end{array}$ & 318 (69) & $110(53) *$ \\
\hline If I make a serious error, I do not worry that I will face disciplinary action. & $204(45)$ & $46(22)^{*}$ \\
\hline It is not difficult to question the decisions or actions of those with more authority. & $126(28)$ & $24(17)^{*}$ \\
\hline $\begin{array}{l}\text { In clinical/simulation settings, discussion around adverse events focuses mainly } \\
\text { on system-related issues, rather than focusing on the individual(s) most } \\
\text { responsible for the event. }\end{array}$ & 296 (65) & $50(24)^{*}$ \\
\hline $\begin{array}{l}\text { Mean summary score for the seven questions above based on a scale from } 1 \\
\text { (strongly disagree) to } 5 \text { (strongly agree). }\end{array}$ & 3.34 & 3.0 \\
\hline
\end{tabular}

$* p>.05$

One main difference between the two groups of students is in confidence levels to speak up on patient safety events. With $78 \%$ of diploma students fearing punitive repercussions when making an error this could negatively affect their willingness to admit and report an error that could easily result in harm to patients. It has been found that fear is a deterrent from error reporting and that this in turn prevents improvements to the system and ultimately improvement to the quality of patient care. ${ }^{[24-26]}$ Fifty-five percent of degree students also fear punitive repercussions and therefore it is an area that still needs work within both types of programs, albeit with practical nursing programs in more immediate need.

\subsection{Implications for educational programs - theory and clinical settings}

Education initiatives could be instituted that focus on the accountability requirement for nurses both professionally and personally and should be seamlessly applied within both theory and clinical settings. Nurses are a respected profession and have the obligation to report errors regardless of fears. Offering training sessions that help students to gain the skillset to be able to speak up could prove fruitful. This could include self-esteem and self-awareness training as these attributes are known to influence confidence. Emphasizing the greater picture of 'patient safety' would help to educate students that patients are paramount. Since $76 \%$ of the diploma students reported that errors were viewed as individual mistakes within their educational program it is important to introduce and highlight the systems perspectives on patient safety into practical nursing programs. Systems' thinking follows the premise that the healthcare system is complex, dynamic and an interdependent whole. ${ }^{[10,11]}$ Systems perspective transfers blame from the individual to the system that allowed the error to take place. ${ }^{[10,11]}$ Understanding the barriers to the dissemination and uptake of knowledge about the systems perspective of patient safety would facilitate the development of more successful strategies to transfer this knowledge. Faculty and clinical instructors need to embrace their responsibility to reduce student fears and the relationship between the clinical supervision and the student is known to be an important factor relating to the development of the student and ultimately the quality of care the patient's receive. ${ }^{[27]}$ This could mean ensuring they are more approachable and that errors are viewed as teachable opportunities. These teachable moments should involve debriefing and reflective practice tasks. Interestingly, students in both types of programs expressed 'neutral' levels on confidence on event analysis and reflective practice as a way to prevent re- 
current issues. A positive learning environment that focuses on learning from the error rather than pointing fingers would be very positive. Simulation is an effective way to move novice nurses forward and can be low or high fidelity ranging from strategies aimed to enhance communication skills to actions requiring high level nursing interventions. ${ }^{[28,29]}$

Confidence to manage conflicts is an area that students enrolled in both types of programs expressed as 'neutral'. Interprofessional activities that educate on role clarification could help to minimize the struggles with conflict management as role blurring is a known issue in nursing. ${ }^{[30,31]}$ This could take place in the simulation environment, classroom setting, and/or clinical setting. Communication classes could be focused on teaching effective techniques that are focused on dispute resolution and effective management of conflict would benefit the entire health care team. In terms of patient safety, the benefit of effective, clear communication on patient outcomes should be stressed.

Strategies that emphasis the role of human factors in patient safety should be targeted within practical nursing programs. These students did not express that they were confident in relation in this. With today's world becoming so fast paced and complex, stressing the requirement for self-care is important. Nurses are known to take care of others and this may not always allow for ample self-care. Professors could inform students of its direct relationship to patient outcomes. Professors should role model this to students to help in promoting understanding and valuing of this practice.

\subsection{Implications for policy development}

Low rates of students in both programs expressed that there is consistency in how preceptors deal with student issues. Program policies should be developed to ensure that management of issues is fair and consistent. This would help students and clinical instructors in managing issues. If policies and procedures are developed and implemented consistently student fears to report may be reduced because the students will be more informed and aware of what the consequences are as opposed to fearing unknown repercussions. These policies and procedures need to be properly developed and thoroughly reviewed to ensure compliance with safety and application legislation, student rights, and ethical standards. The development and perfection of these policies should not be taken lightly as they will be the foundation for managing issues in the future. This open knowledge of how errors will be managed through policies and processes will aid clinical instructors in managing issues as it will provide them with needed guidance and support. The academic institution and nursing professors, through the implementation and utilization of clear and precise policies on error management could

Published by Sciedu Press also benefit as they will have documentation of the policies and the evidence of their actions in accordance with policy requirements.

\subsection{Strengths and limitations}

This study's large sample size plus the inclusion of students from multiple sites and programs helped to ensure a more representative sample of nursing students, and included a higher than expected response rate for on-line surveys. ${ }^{[32]}$ The inclusion of diploma students' perspectives is an advantage of this study as their voices were limited in previous studies. Since the researcher had no relationship with the students, social desirability bias was likely minimized. Response bias may be present because the students who chose to participate may be those that are most interested in patient safety. The cross-sectional design is a study limitation because it presents a snapshot of the participants' perceived confidence at a single time and confidence is dynamic and often changes. The self-reporting nature of the data collection tool has the potential for responder bias. Interpretation of this study's findings is limited to the programs and participants in the study and caution should be taken when generalizing these findings.

\section{CONCLUSIONS AND RECOMMENDATIONS FOR FUTURE RESEARCH}

This study highlighted the need for further investigation with both categories of students regarding their fear of speaking up when they make an error. Research that explores what factors inhibit or enhance students' comfort in disclosing their errors could help to focus future interventions. Interviewing students may help to clarify the nature of the students' concerns and guide further research in this area. Initiatives that incorporate strategies for reducing the fear of disclosure need to be implemented and investigated in future research studies. More emphasis on system issues and their contribution to the occurrence of errors should be incorporated into the education and practice settings to de-emphasize the sole responsibility of the healthcare provider in the occurrence of an error. This area needs more investigation since the current literature has emphasized the importance of recognizing the relationship between system aspects and improvements to patient care and system vulnerability. ${ }^{[33]}$ Additional research on other academic programs from a more global perspective would provide valuable insight. Educational programs need to stress accountability and reporting of errors is needed to change and improve systems including those that have the potential to reduce student fears.

\section{CONFLicts OF INTEREST Disclosure}

The author declares that there is no conflict of interest. 


\section{REFERENCES}

[1] Institute of Medicine. To err is human: Building a safety health system. National Academies Press, Washington. 2000.

[2] Makary MA, Daniel M. Medical error - the third leading cause of death in the US. BMJ. 2016 May; 353: i2139. https://doi .org/ $10.1136 / \mathrm{bmj}$. i2139

[3] Baker GR, Norton PG, Flintoft V, et al. The Canadian adverse events study: The incidence of adverse events among hospital patients in Canada. CMAJ. 2004 May; 170(11): 1678-86. https: //doi.org/10.1503/cmaj.1040498

[4] Blais R, Sears NA, Doran D, et al. Assessing adverse events among home care clients in three Canadian provinces using chart review. BMJ Qual Saf. 2013 Dec; 22(12): 989-97. https : //doi.org/10 $.1136 /$ bmjqs-2013-002039

[5] Canadian Patient Safety Institute. Safety at home: A PanCanadian home care safety study. 2013. Available from: http://www . patientsafetyinstitute.ca/English/re search/commissionedResearch/SafetyatHome/Docum ents/Safety $\% 20$ At $\% 20$ Home $\% 20$ Care.pdf PMid:21105794 https://doi.org/10.1056/NEJMsa1004404

[6] Institute of Medicine. Crossing the quality chasm: A new health system for the 21st century. National Academies Press, Washington. 2001.

[7] Institute of Medicine. Health professions education: A bridge to quality. National Academies Press, Washington. 2003.

[8] Institute of Medicine. Keeping patients safe: Transforming the work environment of nurses. National Academies Press, Washington. 2004

[9] Australian Council for Safety and Quality in Healthcare. National patient safety education framework. 2005. Available from http://www.safetyandquality.gov.au/wp-content/upl oads/2012/06/National-Patient-Safety-Education-Fra mework-2005.pdf

[10] Frank J, Brien S. The Safety Competencies Steering Committee. The safety competencies: Enhancing patient safety across the health professions. Canadian Patient Safety Institute, Ottawa, Ontario. 2008.

[11] World Health Organization. Conceptual framework for the international classification for patient safety. 2009. Available from: http://www. who.int/patientsafety/taxonomy/icp s_full_report.pdf

[12] Landrigan CP, Parry GJ, Bones CB, et al. Temporal trends in rates of patient harm resulting from medical care. N Eng J Med. 2010 Nov 363(22): 2126-34

[13] Smits M, Zegers M, Groenewegen PP, et al. Exploring the causes of adverse events in hospitals and potential prevention strategies. BMJ Qual Saf. 2010 Oct; 19(5): 1-7.

[14] College of Nurses of Ontario. Registration requirements. 2014 Available from: http://www.cno.org/become-a-nurse/new - applicants1/outside-canada/registration-requireme nts-for-rns-and-rpns/

[15] Registered Nurses Association of Ontario. n.d. Types of Nursing Available from: http://rnao.ca/about/types-nursing

[16] Health Authorities Health Professions Act Regulations Review Committee. Toward increased integration of LPNs into health authority employment settings: Four discussion papers by the Health Authorities Health Professions Act Regulations Review Committee. 2002. Available from: http://www.clpna.com/wp-content/u ploads/2013/02/doc_HPA.pdf
[17] College of Nurses of Ontario. RN and RPN practice: The client, the nurse and the environment. 2014. Available from: http://www.cn o.org/globalassets/docs/prac/41062.pdf

[18] Registered Practical Nurses Association of Ontario, n.d. Available from: https://www.rpnao.org/about/history

[19] College of Nurses of Ontario. Membership statistics highlights 2014 2015. Available from: http://www.cno.org/Global/docs/ge neral/43069_stats/43069_MembershipStatistics-Highl ights.pdf

[20] Duhn L, Karp S, Oni O, et al. Perspectives on patient safety among undergraduate nursing students. J Nurs Educ. 2012 Sep; 15(9): 52631. https://doi .org/10.3928/01484834-20120706-04

[21] Ginsburg L, Castel E, Tregunno D, et al. The H-PEPSS: An instrument to measure health professionals' perceptions of patient safety competence at entry to practice. BMJ Qual Saf. 2012 Apr; 21(8): 676-84. https://doi.org/10.1136/bmjqs-2011-000601

[22] Doyle P, Van den Kerkhof EG, Edge DS, et al. Self-reported patient safety competence among Canadian medical students and postgraduate trainees: A cross-sectional study. BMJ Qual Saf. 2015 Nov; 24: 135-41. https://doi.org/10.1136/bmjqs-2014-003142

[23] Perry P. Concept analysis: Confidence/self-confidence. Nurs Forum. 2011 Oct-Dec; 46(4): 219-230. PMid:22029765 https : //doi .or $\mathrm{g} / 10.1111 / \mathrm{j} .1744-6198.2011 .00230 . \mathrm{x}$

[24] Dunn KE. Insight into error hiding: Exploration of nursing student's achievement goal orientations. J Nurs Educ. 2014 Feb; 53(2): 93-6 https://doi.org/10.3928/01484834-20140122-02

[25] Mayo AM, Duncan D. Nurse perceptions of medication errors: What we need to know for patient safety. J Nurs Care Qual. 2004 Sep; 19(3): 209-17. PMid:15326990 https://doi.org/10.1097/00 001786-200407000-00007

[26] Ulanimo VM, O’Leary-Kelley C, Connolly PM. Nurses' perceptions of causes of medication errors and barriers to reporting. $\mathrm{J}$ Nurs Care Qual. 2007 Jan-Mar; 22(1): 28-33. PMid:17149082 https://doi.org/10.1097/00001786-200701000-00007

[27] Amsrud KE, Lyberg AL, Severinsson E. The influence of clinical supervision and its potential for enhancing patient safety Undergraduate nursing students' views. 2015 Feb; 5(6): 87-95. https : //doi .org/10.5430/jnep.v5n6p87

[28] Galloway SJ. Simulation techniques to bridge the gap between novice and competent healthcare professionals. OJIN. 2009 May; 14(2): Manuscript 3.

[29] Aebersold M, Tschannen D. Simulation in nursing practice: The impact on patient care. OJIN. 2013 May; 18(2): Manuscript 6

[30] Eppich W. "Speaking up" for patient safety in the pediatric emergency department. Clin Pediatr Emerg Med. 2015 Jun; 16(2): 83-9.

[31] Malloch K, Ridenour J. Views on scope of practice: Is it time for a continuum-based population-driven model? Nurs Adm Q. 2014 Apr-June; 38(2): 192-94. https ://doi .org/10.1097/NAQ.0000 000000000030

[32] Dillman DA. Mail and internet surveys: The tailored design method (2nd ed.). John Wiley \& Sons, Hoboken. 2007.

[33] Hashemi F, Nasrabadi AN, Asghari F. Factors associated with reporting nursing errors in Iran: A qualitative study. BMC Nurs. 2012 October; 11(20): 1-8. https : //doi.org/10.1186/1472-6955-11-2 